\title{
MINERAÇÃO E CAPTURA REGULATÓRIA: \\ A ESTRATÉGIA DA ANGLO AMERICAN EM \\ CONCEIÇÃO DO MATO DENTRO (MG), BRASIL
}

\section{MINING INDUSTRY AND REGULATORY CAPTURE: ANGLO AMERICAN'S STRATEGY IN CONCEIÇÃO DO MATO DENTRO (MG), BRAZIL}

\author{
Bruno Milanez \\ Rodrigo Salles Pereira dos Santos"*
}

\section{Introdução ${ }^{1}$}

No Brasil, o período compreendido pelos dois primeiros governos do presidente Lula da Silva (2003 - 2010), coincidiu, grosso modo, com o chamado boom das commodities. A despeito do discurso neodesenvolvimentista que o permeou, este período esteve associado a um aprofundamento de características neoextrativistas, não apenas decorrentes de decisões de política econômica
(MILANEZ; SANTOS, 2015), como também devido ao esvaziamento dos órgãos de fiscalização ambiental, ajustes discricionários e flexibilização na implementação da legislação ambiental e relaxamento na aplicação da lei em relação a grandes empresas, de forma a favorecer a implantação e ampliação de projetos extrativistas.

Considerando o contexto político e econômico mais amplo do período, o artigo debate o papel do Estado e das corporações

\footnotetext{
* Professor do Departamento de Engenharia de Produção e Mecânica e do Programa de Pós-graduação em Geografia (PPGEO) da Universidade Federal de Juiz de Fora - UFJF - (Juiz de Fora/MG/Brasil). Doutor em Política Ambiental. E-mail: bruno.milanez@ufj.edu.br

*** Professor do Departamento de Sociologia e do Programa de Pós-graduação em Sociologia e Antropologia (PPGSA) da Universidade Federal do Rio de Janeiro - UFRJ - (Rio de Janeira/RJ/Brasil) . Doutor em Ciências Humanas (Sociologia). E-mail: santosrodrigosp@gmail.com

1. Os autores agradecem a Fundação de Amparo à Pesquisa do Estado do Rio de Janeiro (FAPERJ), a Fundação de Amparo à Pesquisa do Estado de Minas Gerais (FAPEMIG) e o Conselho Nacional de Desenvolvimento Científico e Tecnológico (CNPq) pelo apoio à pesquisa em que se baseia este trabalho.
} 
a partir da uma perspectiva de redes globais de produção dos recursos naturais (BRIDGE, 2008; WILSON, 2013), privilegiando uma análise em escala regional e centrada no agente econômico. Assim, pretendemos contribuir tanto para o debate sobre o papel do Estado na regulação do acesso aos bens minerais, bem como para as estratégias das empresas transnacionais extrativas.

Usamos como exemplo emblemático a implantação do Projeto Minas-Rio (PMR), proposto pela empresa brasileira MMX e concluído pela sul-africana Anglo American (AA). Nosso foco será na implantação da mina do PMR, em Conceição do Mato Dentro. Este município se localiza a 160 $\mathrm{km}$ de Belo Horizonte (capital do estado de Minas Gerais) e, em 2010, possuía cerca de 18 mil habitantes, dos quais 31\% viviam em área rural (IBGE, 2016). 0 estudo tem por marcos temporais a chegada da MMX em Conceição do Mato Dentro (2006) e a concessão das licenças prévia (2008), de instalação (2010) e de operação (setembro de 2014) ${ }^{2}$, incluindo o carregamento da primeira remessa de minério para o exterior (outubro de 2014).

A pesquisa, de orientação qualitativa, foi realizada por meio de visitas de campo, observação participante, levantamento documental e entrevistas com roteiro semiestruturado e/ou informais, e buscou analisar as relações entre a AA, o Estado e os ór- gãos de licenciamento ambiental, e os movimentos sociais. 0 levantamento de dados se restringiu ao estado de Minas Gerais e ao município de Conceição do Mato Dentro.

0 artigo está organizado em 4 seções, além desta introdução e de suas considerações finais. A seção 1 faz uma contextualização do boom das commodities e de seu encerramento, com foco no setor de minério de ferro, e esquematiza o comportamento das empresas tanto no período de expansão, quanto de retração da demanda. A seção seguinte descreve a rede de produção do setor extrativo mineral no Brasil; para tanto, a seção apresenta a estrutura da oferta brasileira e explicita as condições da entrada da AA, comentando o quadro institucional de regulação ambiental no estado de Minas Gerais. Na seção 3, fazemos uma breve apresentação da AA e contextualizamos as decisões de investimento e desinvestimento no PMR no contexto mais geral da empresa e das fases de boom e pós-boom das commodities. A seção 4 analisa algumas das estratégias de exercício do poder corporativo sobre órgãos estatais e comunidade, traçando paralelos entre essas ações e práticas semelhantes desenvolvidas por outras mineradoras no país. Por fim, na última seção, sistematizamos os principais resultados e conclusões da pesquisa.

2. O licenciamento ambiental no Brasil, de forma geral, é concedido em três etapas. Após apresentar estudos preliminares, bem como o Estudo de Impacto Ambiental (EIA), a empresa solicita a Licença Prévia (LP), na qual é avaliada a viabilidade ambiental do projeto. Uma vez de posse dessa licença, a empresa deve fazer o detalhamento dos projetos de engenharia e solicitar a Licença de Instalação (LI), que permite iniciar as obras. Com a conclusão da construção, uma vez feitas as devidas auditorias, a empresa pode obter a Licença de Operação (LO), que autoriza o início das atividades. 
1. A economia mineral na virada do século

\subsection{0 boom das commodities}

A elevação expressiva dos preços de um amplo conjunto de bens padronizados e intensivos em recursos naturais em diversos mercados de alcance mundial entre 2002 e 2008 é caracterizada, grosso modo, como o primeiro boom das commodities do século XXI (CONCEIÇÃO; MARONE, 2008). Da perspectiva dos bens minerais, no entanto, a inflexão positiva dos preços se prolongou até 2011, permitindo caracterizar uma dinâmica própria. A elevação contínua dos níveis de preço e investimento minerais esteve apoiada, desde o início do período, na participação global da China no consumo mundial de minérios, que chegou a atingir cerca de 80\% no caso do minério de ferro (COMMODITIES NOW, 2015).

Analisando os dados compilados pelo Banco Mundial, a curva dos preços nominais das commodities minerais adquiriu uma forma ascendente impressionantemente inclinada a partir dos anos 2000, refletindo a elevação dos níveis de preços dos principais minerais, em especial o ouro, o estanho, o níquel e o zinco. A evolução dos preços reais, embora mais modesta, refletia níveis de crescimento bastante expressivos nos casos da prata, estanho, ouro, minério de ferro e cobre entre 2002 e 2011 (WORLD BANK, 2016). No caso específico do minério de ferro, a ascensão dos preços reais se iniciou em 2002 (US\$ 38,73 por tonelada), tendo atingido seu primeiro pico em 2008 (US\$ 151,69). Após desabar durante a crise financeira global de 2008-2009, tendo atingido US\$ 82,91, uma nova inflexão positiva na trajetória dos preços de minério de ferro impulsionou um novo recorde, atingindo US\$ 153,99 em 2011 (WORLD BANK, 2016).
A evolução do investimento em bens de capital na indústria extrativa mineral no mundo seguiu um tanto tardiamente a trajetória dos preços. Desse modo, as despesas de capital voltadas à expansão da capacidade produtiva atingiram seu nível mais baixo em 2002 (FELLOWS, 2015). Desde então, os investimentos em sustentação da atividade, em expansão de infraestruturas já existentes e em projetos greenfield se intensificaram de maneira constante, atingindo o pico de cerca de US\$ 220 bilhões em 2012 (COMMODITIES NOW, 2015). No que concerne à distribuição regional desses investimentos, a América Latina ampliou consideravelmente sua participação no investimento mineral mundial no período, atingindo 32\% (US\$ 180 bilhões) do total em 2010 (ELLA, 2012).

0 PMR foi concebido tipicamente como um projeto greenfield de exportação por parte de um novo player setorial - a MMX - no contexto de elevação de preços e, consequentemente, da expansão do financiamento para o setor. Nesse caso específico, o aumento dos preços reais do minério de ferro em 297,6\% entre 2002 e 2011 (WORLD BANK, 2016) conformou um contexto favorável ao investimento na exploração da mina de Sapo-Ferrugem, caracterizada por "reservas de 1,5 bilhão de toneladas, com teor de 37,9\% de óxido de ferro $\left(\mathrm{Fe}_{2} \mathrm{O}_{3}\right)$ " (CETEM, 2012), e vida útil de cerca de 40 anos; assim como em suas infraestruturas associadas, mineroduto e porto.

Além disso, a aquisição dos ativos do PMR por parte da AA em 2007 refletia uma tendência mais ampla de centralização de capitais no setor, cujas fusões e aquisições transnacionais triplicaram entre 2002 e 2011 (UNTD, 2016), assim como sinalizava uma estratégia de reposicionamento setorial da corporação via diversificação territorial e de mercado. Retrospectivamente, a mídia especializada 
avalia que àquela altura "era evidente que a Anglo estava perdendo a oportunidade do boom das commodities, e algo tinha de ser feito" (COHEN, 2016) de modo a sustentar sua posição como global player setorial.

Entretanto, o final do período considerado apresentava sinais combinados de maturação dos investimentos na expansão da oferta global à desaceleração da demanda chinesa por minérios, incidindo particularmente sobre o setor de construção civil e as indústrias de bens de capital e de bens de consumo duráveis (em especial, a automobilística) (ROBERTS et al., 2016), prenunciando um declínio consistente de preços e investimentos na indústria extrativa mineral no mundo.

\subsection{0 pós-boom das commodities}

"O boom dos preços das commodities acabou e qualquer um com metade de um cérebro sabe disso" (THE TELEGRAPH, 2012). Quando essa declaração foi feita em agosto de 2012, Martin Ferguson, então Ministro dos Recursos e Energia da Austrália, respondia à inquietação da opinião pública diante do declínio acentuado dos preços dos principais minérios exportados pelo país carvão e ferro - e de seus efeitos recessivos. A percepção do fim do boom ainda era pouco clara diante da recuperação significativa em relação à queda dos preços em 2009 (cf. Gráfico 1). Ademais, analistas de mercado e corporações mineradoras se engajaram ativamente em reconstruir a confiança na continuidade da fase ascendente, produzindo importante efeito performático. A partir de 2012, no entanto, nenhum dos principais minérios comercializados em mercados internacionais ficaria imune à queda tendencial de preços, tornando forçoso o reconhecimento de seu encerramento.

Gráfico 1. Índice de Preços das Commodities Minerais por segmento (2001-2015)

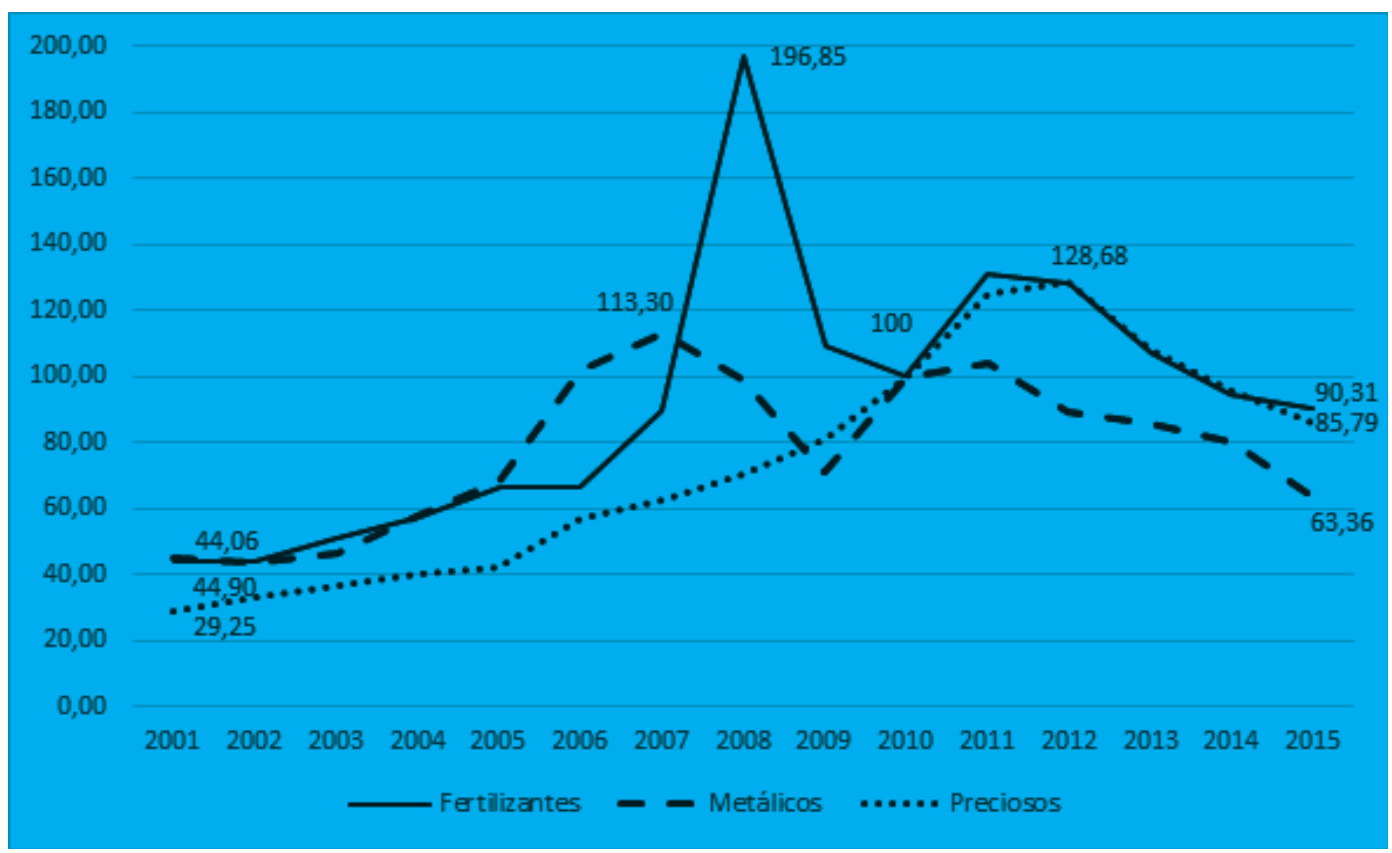

Fonte: World Bank (2016). 
Embora a evolução negativa dos preços desde 2012 tenha afetado toda a indústria extrativa mineral (IEM), as expressões da queda em mercados de minérios específicos foram diferenciadas. Em primeiro lugar, destaca-se a divergência temporal dos níveis máximos dos preços dos minerais metálicos (2007), fertilizantes (2008) e, principalmente, metais preciosos (2012), cuja demanda tende a ser definida predominantemente por necessidades de consumo conspícuo e pela função de reserva de valor (WANDERLEY, 2015). Em segundo lugar, tendo como referência o ano de 2010, é possível perceber que a diferença entre os extremos de preços dos minerais metálicos $(159,2 \%)$ é consideravelmente inferior às distâncias observadas nos casos dos metais preciosos $(339,9 \%)$ e dos fertilizantes (346,8\%). Por sua vez, embora a velocidade da queda tenha sido muito expressiva no segmento de metais preciosos, seus impactos foram mais significativos entre os fertilizantes $(-54,1 \%)$ e os minerais metálicos $(-44,1 \%)$. Finalmente, é importante observar que em nenhum dos três segmentos os preços finais (2015) cederam abaixo dos níveis de 2001, permanecendo relativamente altos para os minerais metálicos $(41,1 \%)$, fertilizantes (105\%) e, especialmente, metais preciosos $(193,3 \%)$.

Desde 2012, o mercado mundial de minérios passou a apresentar, portanto, uma situação recessiva sistêmica, com algumas características distintivas. Em primeiro lugar, os desequilíbrios de mercado no setor remetiam a uma reversão fundamental da relação entre oferta e demanda de bens minerais. Dado o horizonte de médio prazo do investimento mineral, alterações na demanda tenderiam a impactar de modo desproporcional a oferta, de natureza inelástica (COELHO, 2016, p. 175-6). Desse modo, a referida maturação de investimentos na oferta de minérios - no caso do minério de ferro, a capacidade produtiva mundial havia saltado de 1,13 para 1,85 bilhão de toneladas anuais entre 2002 e 2012 (IISI, 2014; WSA, 2014) - se defrontou com a retração nas condições da demanda no principal mercado consumidor de minérios, promovendo uma perspectiva de preços baixos no longo prazo.

Por sua vez, a mútua influência exercida pela natureza cíclica dos mercados de minérios e o condicionamento financeiro das decisões dos agentes econômicos do setor impulsionou a precipitação da implantação de projetos extrativos de larga escala, sendo decisiva na conformação de problemas de endividamento para a aquisição de ativos por parte de grandes mineradoras na fase de elevação dos preços. Se, de um lado, a reversão do ciclo de preços e a redução da receita das principais companhias mineradoras tornaram a amortização das dívidas contraídas mais complexa, de outro lado, reduziram sensivelmente as condições de sustentação dos níveis prévios de remuneração aos acionistas.

Análises especializadas acerca do desempenho de corporações mineradoras em mercados de capitais vêm defendendo que, a despeito do discurso performático centrado na ampliação dos negócios, observa-se um efeito de "perda do apetite" (NIEPONICE et al., 2015) dos investidores por ações de mineradoras já há algum tempo. Desse modo, a análise feita pelo Boston Consulting Group (BCG) do desempenho das 101 maiores companhias mineradoras do mundo entre 2010 e 2014 no que diz respeito ao pagamento de dividendos revelou "que essas empresas distribuíram um retorno total ao acionista de $-18 \%$ a cada ano" (NIEPONICE et al., 2015). Esse desempenho é 
explicado, de modo geral, pela combinação entre custos unitários elevados no cenário do boom e declínio das margens de lucro após seu encerramento.

Como é possivel observar no Gráfico 2, a evolução dos preços das ações ordinárias de três das maiores corporações mineradoras listadas na London Stock Exchange - Anglo American plc. (AAL.L), BHP Billiton plc. (BLT.L) e Rio Tinto plc. (RIO.L) - é exemplar desta tendência, apresentando trajetória descendente similar desde 2012. Entretanto, enquanto as ações de Rio Tinto e BHP Billiton perderam, respectivamente, cerca de 30,9\% e 50,5\% de seu valor no mercado de capitais londrino, as ações da AA observaram uma inflexão negativa ainda mais acentuada, chegando a perder $67,7 \%$ do valor entre janeiro de 2012 e julho de 2016 (SANTOS; MILANEZ, 2016).

Gráfico 2. Evolução dos preços de ações ordinárias de corporações mineradoras selecionadas, London Stock Exchange (2012-2016)

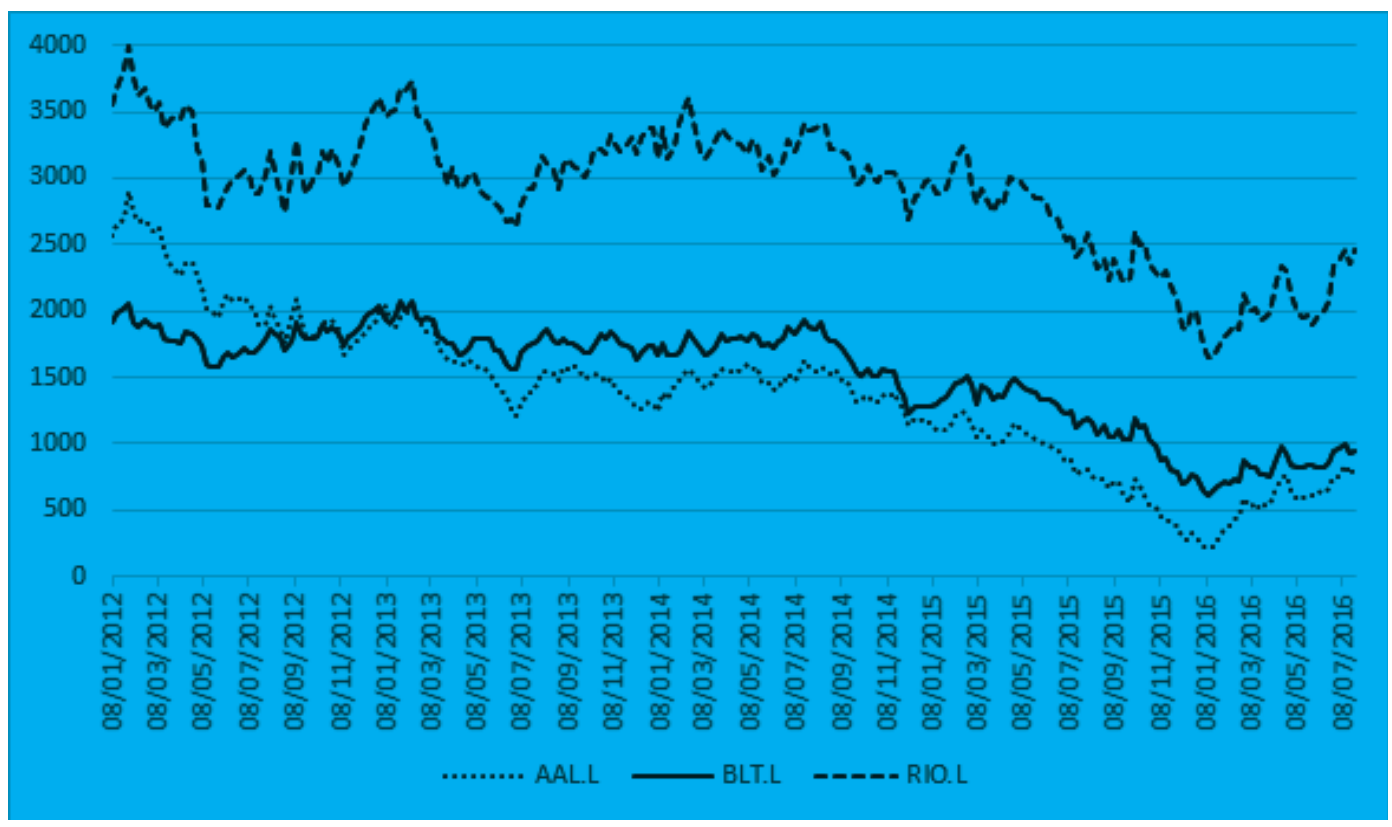

Fonte: Santos e Milanez (2016).

Alguns analistas consideraram a aquisição do PMR como central nessa involução na imagem da AA diante dos investidores em anos recentes, tendo se mostrado uma aposta desastrosa que se combinou às tendências estruturais do setor. Vista como uma decisão de investimento crucial na trajetória da AA, seus custos excederam as previsões da corporação, de modo que "um projeto de US\$ 3 bilhões, custou em última análise aproximadamente US\$ 8,3 bilhões e sobrecarregou a empresa com cerca de US\$ 14 bilhões em dívidas" (COHEN, 2016).

0 contexto de pressões financeiras e operacionais que incidiu sobre a AA foi, em grande medida, explicativo das mudanças em sua estratégia corporativa. A venda dos negócios da AA em fosfato e nióbio para a 
China Molybdenum Co. (CMOC) por US $\$ 1,5$ bilhão (LOPES; ROSTÁS, 2016) em 2016; a indecisão acerca da venda do controle da Kumba Iron Ore Ltd., na África do Sul; e o esforço, até então infrutífero, em torno da transferência do PMR, no Brasil (PATTERSON; MACDONALD, 2016) seriam elucidativos da reorientação defensiva da corporação a partir do fim do boom das commodities.

Observou-se, assim, a partir do pós-boom, um processo de reversão da trajetória das despesas de capital no setor, que "declinou mais de 20\% desde seu pico em 2012” (NIEPONICE et al., 2015), e uma avaliação estrita de sua estrutura, provocando o redimensionamento, postergação e o cancelamento de projetos extrativos e, em especial, a transferência de ativos-chave, tendo em vista uma orientação mais geral de reespecialização das maiores mineradoras em seus core businesses originários.

Desse modo, "desinvestimentos e atividades relacionadas também cresceram no período de 2010 a 2014, à medida que as companhias venderam ativos non core que não mais se alinhavam a sua estratégia mais ampla” (NIEPONICE et al., 2015) e, consequentemente, sustentaram parcialmente suas condições de oferecer retornos aos acionistas em nível substancial. Considerando a demanda contraída para transferência, corporações como a Vale chegaram mesmo a se desfazer de ativos a preço "simbólico", como no caso da mina de carvão Isaac Plains, na Austrália, vendida à Stanmore Coal em 2015 (GÓES; ROSAS, 2015).

No que diz respeito ao minério de ferro, essas pressões foram acentuadas em face das estratégias corporativas definidas pelas três maiores companhias do segmento, Vale, BHP Billiton e Rio Tinto, que focalizaram a ampliação das escalas de extração e a consequente elevação da produtividade.
Desse modo, considerando o controle semioligopólico das big three sobre as reservas de ferro de classe mundial, "seus custos operacionais [...] são baixos o bastante para que consigam manter uma margem razoável em cada tonelada vendida, apesar dos preços baixos, graças às economias de escala" (HOYLE, 2015). Nas palavras de Jimmy Wilson, então Presidente da Divisão de Minério de Ferro da BHP Billiton: "Se reduzirmos o volume, ele será preenchido por outras empresas. No fim do dia, estaremos penalizando, em essência, nossos acionistas" (HOYLE, 2015). Nesse sentido, estratégias defensivas de preservação dos níveis de retorno aos acionistas e ofensivas de "expulsão" de competidores caracterizados por níveis de custos relativamente altos na fase de pós-boom foram agravando as condições operacionais de corporações como a AA.

É possivel observar, ainda, estratégias específıcas de diversificação operacional restrita na indústria extrativa mineral, via ingresso de mineradoras major "em operações que apresentam pequenas margens de retorno e são tradicionalmente dominadas pelos intermediários do setor, numa tentativa de encontrar novas fontes de receita” (PUK0, 2015). Como exemplos, poderiam ser citados o envolvimento da Rio Tinto no refino de cobre para outras empresas, maximizando o uso de sua capacidade instalada de processamento; o início de operações de blendagem de minério de ferro por encomenda para siderúrgicas com vistas à obtenção de premium prices; e a internalização das atividades de distribuição e vendas dos metais do grupo platina por parte da própria AA (PUK0, 2015).

Embora tenha havido variações importantes, desde o pós-boom das commodities em 2012, as mineradoras líderes no segmento do minério de ferro foram reconcentrando os focos de negócio. Para tanto, busca- 
ram enfrentar a dependência da elasticidade da demanda através de economias de escala crescentes (LEIJH, 2013) e de "formas mais simples e imediatas de elevação [da produtividade] - tais como corte de custos fixos ou foco em zonas minerais de alta concentração [mineral] em suas operações" (NIEPONICE et al., 2015). De modo geral, a combinação do cenário de pós-boom e das estratégias corporativas das big three no segmento ferrífero explicaram grande parte da escalada das dificuldades pelas quais passou a AA no Brasil no início dos anos 2010.

\section{Contexto operacional da mineração no Brasil}

\subsection{Contexto corporativo}

A extração de minério de ferro no Brasil é realizada tipicamente em minas a céu aberto, estando concentrada nos estados de Minas Gerais (68\%) e Pará (30\%) (DNPM, 2015). Conforme apresentado na Tabela 1, o setor é altamente concentrado; os dados mostram que a Vale S.A. (Vale) responde por cerca de $80 \%$ da extração do minério, de modo que sua principal competidora, a Companhia Siderúrgica Nacional S.A. (CSN) e sua subsidiária Nacional Minérios S.A. (Namisa) atingiram conjuntamente a participação de apenas 8\% em 2014. Ambas as empresas, Vale e CSN, são ex-estatais, privatizadas nos anos 1990; assim, sua hegemonia se deve, em parte, à estratégia desenvolvimentista vigente no Brasil até fins dos anos 1970, que lhes garantiu acesso e controle privilegiado a reservas minerais de classe mundial.

Os dados demonstram uma participação limitada da AA, por ela ter feito seu primeiro carregamento em 2014. Em 2015, embora ainda em processo de ramp-up, ela atingiu o marco de 9,2 milhões de toneladas (Mt) (ANGLO AMERICAN, 2016), o que a colocaria entre as três maiores empresas do setor no Brasil.

Tabela 1: Principais empresas do setor de minério de ferro no Brasil

\begin{tabular}{|l|c|c|c|c|c|c|}
\hline \multirow{2}{*}{ Empresa } & \multicolumn{2}{|c|}{2011} & \multicolumn{2}{c|}{2013} & \multicolumn{2}{c|}{2014} \\
\cline { 2 - 7 } & Produção (Mt) & $\%$ & Produção (Mt) & $\%$ & Produção (Mt) & $\%$ \\
\hline Vale & 311,8 & 85 & 299,8 & 77 & 319,2 & 80 \\
\hline CSN/Namisa & 20,1 & 5 & 25,7 & 7 & 33,0 & 8 \\
\hline Gerdau & N/D & N/D & 11,5 & 3 & 7,6 & 2 \\
\hline Cia de Mineração Serra Azul & N/D & N/D & 6,0 & 2 & 6,0 & 2 \\
\hline Usiminas & 6,3 & 2 & 7,0 & 2 & 6,0 & 2 \\
\hline VEtM & N/D & N/D & 4,0 & 1 & 4,0 & 1 \\
\hline Ferrous Resources & N/D & N/D & 5,1 & 1 & 3,8 & 1 \\
\hline MMX & 7,5 & 2 & 5,9 & 2 & 2,7 & 1 \\
\hline Arcellor Mittal & N/D & N/D & 4,3 & 1 & 2,6 & 1 \\
\hline Minérios Itaúna Ltda & N/D & N/D & 2,3 & 1 & 2,0 & 1 \\
\hline Zamin & N/D & N/D & 6,0 & 2 & 1,5 & 0 \\
\hline Vetria Mineração & N/D & N/D & 1,5 & 0 & 1,0 & 0 \\
\hline Samarco* & 23,2 & 6 & N/D & & N/D & \\
\hline Anglo American & 0,0 & 0 & 0,0 & 0 & 0,7 & 0 \\
\hline Outros & 0,0 & 0,0 & 12,0 & $3 \%$ & 8,6 & 2 \\
\hline Total & 368,9 & 100 & 391,1 & 100 & 398,7 & 100 \\
\hline
\end{tabular}

Fonte: (IBRAM, 2012; 2015)

* Para os anos de 2013 e 2014, a produção da Samarco foi tratada separadamente pelo IBRAM como pelotas, não tendo sido incluída nas estatísticas gerais 
0 beneficiamento do minério de ferro ocorre próximo às minas, o que reduz os custos logísticos. Portanto, em conjunto com as minas, são implantadas pilhas de estéril e barragens de rejeito. Devido ao grande volume envolvido no comércio de minério de ferro e na sua elevada densidade, o transporte depende de máquinas e equipamentos e da integração de modais de grande capacidade - estradas de ferro ou minerodutos e terminais portuários dedicados, capazes de abrigar navios mineraleiros, no caso da exportação.

Tradicionalmente, o minério brasileiro é transportado por ferrovias, havendo uma forte ligação entre os dois setores. Em 2012, o transporte de minério de ferro e de carvão mineral foi responsável por 76\% do total de carga transportada por trens no país (VILAÇA, 2013). Da mesma forma, a concessão de importantes estradas de ferro do país foi dada a empresas do setor mineral, como Vale e CSN (ANTT, 2012).

Os minerodutos consistem em uma segunda alternativa. Os principais em utilização pertencem à Samarco e ligam suas minas em Minas Gerais às pelotizadoras no estado do Espírito Santo, percorrendo cerca de $400 \mathrm{~km}$. À medida que novas empresas tentaram entrar no mercado durante o boom do minério de ferro, houve um aumento no uso de minerodutos devido ao menor custo operacional e às restrições de acesso criadas pelas mineradoras já instaladas. Assim, a AA implantou um mineroduto percorrendo um total de $525 \mathrm{~km}$ (AGB, 2011). Além desse, existiam projetos de minerodutos pela Ferrous Resources (480 km), pela Manabi $(511 \mathrm{~km})$ e pela Sul Americana de Metais (482 km), alguns deles paralisados após a queda dos preços do ferro.

Apesar da relevância da extração mineral para a economia brasileira, há um forte desequilíbrio entre o consumo doméstico e a exportação de minério de ferro. No ano de 2013, dos 386 Mt de minério de ferro extraídos, cerca de $330 \mathrm{Mt}$ (85\%) foram exportados na forma de minério ou pelotas (DNPM, 2012). O PMR, desenhado para exportar todo o minério extraído, aprofundava esse modelo de inserção internacional regressiva que caracteriza a economia brasileira como exportadora de commodities primárias (MILANEZ; SANTOS, 2015).

\subsection{Contexto institucional}

A extração mineral é uma atividade histórica em Minas Gerais. Ela teve origem com a exploração de ouro no período colonial e se consolidou com a extração de ferro a partir dos anos 1940, principalmente pela atuação da Vale. Em 2013, a indústria extrativa correspondeu a 7,5\% do valor adicionado bruto do estado (IBGE, 2015), atestando sua relevância econômica regional. Não obstante, os papeis histórico e econômico da mineração na formação deste estado são comumente mobilizados para legitimar a manutenção e expansão da atividade (EUCLYDES, 2012). Dessa forma, projetos minerais são associados intencionalmente a entidades abstratas, como o interesse nacional ou o interesse público, de modo a reforçar sua legitimidade, moralizando o comportamento empresarial "em nome do país” e em oposição ao "interesse individual" daqueles que discordam de sua priorização (ZHOURI, 2014).

0 órgão responsável pelo licenciamento ambiental em Minas Gerais é o Conselho Estadual de Política Ambiental (COPAM), que tem por finalidade deliberar sobre diretrizes, políticas, normas regulamentares e técnicas. 0 COPAM integra a estrutura da Secretaria de Estado do Meio Ambiente e 
Desenvolvimento Sustentável (SEMAD), que tem como órgãos executivos a Fundação Estadual de Meio Ambiente (FEAM), o Instituto Mineiro de Gestão das Águas (IGAM) e o Instituto Estadual de Florestas (IEF). A partir de 2006, houve um processo de regionalização do COPAM em Unidades Regionais Colegiadas (URCs), sendo estas apoiadas, técnica e administrativamente, por suas respectivas Superintendências Regionais de Meio Ambiente e Desenvolvimento Sustentável (SUPRAMs). As URCs são, assim como o COPAM, órgãos deliberativos e normativos, porém atuam regionalmente no licenciamento ambiental (VIANA; BURSZTYN, 2010). No caso do PMR, o licenciamento foi realizado pela URC Jequitinhonha.

0 COPAM e as URCs são compostos paritariamente por representantes intra e extragovernamentais. Contudo, o ingresso desses conselheiros está condicionado a sua legitimidade, baseada em recursos sociais, derivados de relações com membros da área; intelectuais, adquiridos de acordo com níveis de reputação acadêmica; ou mesmo de representação. Desta forma, a participação de membros das camadas populares permanece altamente restringida, predominando nestes organismos posturas conservadoras quanto à defesa de direitos territoriais coletivos e, em muitos casos, pró-empreendimentos (CARNEIRO, 2005).
0 poder do setor mineral se faz presente dentro dos órgãos ambientais. No COPAM, dentre os assentos permanentes reservados para a "sociedade civil", além daquele ocupado pela Federação das Indústrias de Minas Gerais (FIEMG), existe outro exclusivo para o Instituto Brasileiro de Mineração (IBRAM), a associação de indústrias mineradoras (COPAM, 2013a). Na URC Jequitinhonha, um assento é ocupado pela FIEMG, mas há outro reservado para o Departamento Nacional de Produção Mineral (DNPM) ${ }^{3}$, autarquia federal responsável por promover a extração mineral (COPAM, 2013b).

Presença semelhante se vê nos órgãos de gestão de recursos hídricos. No Conselho Estadual de Recursos Hídricos, existem assentos exclusivos para a FIEMG, para o IBRAM e ainda para o Instituto Aço Brasil (associação das empresas siderúrgicas) (MINAS GERAIS, 2014). No caso do Comitê de Bacia do Rio Santo Antônio, onde se localiza o PMR, estão presentes as mineradoras Vale, AA e Morro do Pilar Minerais S.A. 0 setor mineral aumenta ainda mais sua influência de forma indireta, uma vez que, entre os conselheiros, também está a Fundação Comunitária de Ensino Superior de Itabira (Funcesi), instituição de ensino que tem a Vale entre seus instituidores (MINAS GERAIS, 2002). 


\section{A Anglo American e o Projeto Minas-Rio}

A AA é uma empresa mineradora com sede no Reino Unido. Ela foi fundada em 1917 na África do Sul para atuar na exploração de ouro e ampliou seus negócios para o segmento de diamantes nos anos 1920, adquirindo, posteriormente, ações do grupo De Beers. A empresa chegou ao Brasil em 1973, desenvolvendo atividades no estado de Goiás nos segmentos de níquel, nióbio e fosfato (ANGLO AMERICAN, 2013).

Com o fim do apartheid, a corporação transferiu parte de seus ativos para o exterior, de forma a evitar sua possível nacionalização (MATTERA, 2008) e, em 1998, moveu sua sede de Johannesburgo para Londres. Desde o início dos anos 2000, reorientou sua atuação com vistas à diversificação territorial e de mercado (RAJAK, 2011; ANGLO AMERICAN, 2015b). Não obstante, ao fim do boom das commodities, a situação efetiva da corporação era caracterizada por dependência territorial, realizando operações extrativas em nove países, mas concentrando $77,6 \%$ de sua força de trabalho global na África do Sul (ANGLO AMERICAN, 2015a); dependência de portfólio, de maneira que o ferro, o manganês, o cobre e o diamante respondiam por cerca de 76\% de seus resultados em 2014 (Anglo American, 2015a); e, finalmente, dependência material, apresentando um modelo de negócios centrado em volume e tempo de extração elevados, vulnerável a ciclos de demanda, o que se tornaria um elemento decisivo para a evolução recente de suas atividades no Brasil.

Nesse sentido, sua posição entre as maiores mineradoras do mundo pode ser explicada, em grande medida, a partir do acesso e controle quase-monopólico de bens naturais e estoques de mão de obra na África do
Sul durante o regime de segregação racial. 0 fato da corporação haver negociado seu primeiro contrato coletivo com o National Union of Mineworkers (que representava os trabalhadores negros) somente em 1983 sugere a criação de valor via extração direta de mais-valia e a auferição de lucros extraordinários a partir do racismo de Estado. Rajak (2011) menciona que, na África do Sul, criou-se uma mitologia sobre a AA, em torno da qual formou-se a imagem de onipresença, pois a empresa seria um agente atuando 'por detrás dos panos' e moldando o país de acordo com sua vontade.

Além disso, a trajetória organizacional da AA também é caracterizada por diferentes conflitos com comunidades, seja por seus impactos ambientais, seja por violação de direitos humanos. Em seu relatório, Mattera (2008) descreve conflitos e impactos na África do Sul, Gana, Zimbábue, Irlanda e EUA. Tais eventos incluiam contaminação de corpos d'água com arsênio, chumbo, mercúrio e zinco; contaminação de pessoas por chumbo e cobre; remoção forçada de comunidades rurais, e fechamento compulsório de caminhos tradicionais em áreas rurais.

Ao longo dos anos 2000, aproveitando o momento de demanda forte por minérios, a AA adotou uma estratégia de multiplicação de investimentos e intensa diversificação. 0 investimento no PMR pode ser entendido dentro desse contexto expansionista. 0 PMR é composto por uma mina de ferro, Sapo-Ferrugem (26 Mt), um mineroduto e um porto para a exportação do minério (100 Mt). Em 2007, a empresa brasileira MMX iniciou sua instalação e, no ano seguinte, vendeu-o para a AA por US\$ 4,5 bilhões, junto com outra mina no Amapá. Depois de fechado o acordo, o projeto se mostrou mais complexo do que o previsto. A pureza do minério era inferior ao indicado e havia 
uma série de condicionantes ambientais a serem cumpridas. A divisão de Engenharia Mineral da AA teria sido contrariada, como sugerem as palavras de um de seus membros sênior: "Nós nunca teríamos aprovado a aquisição, não que nós tivéssemos sido consultados" (COHEN, 2016).

A partir de 2011, a AA começou a apresentar um agravamento sistemático de seus resultados, antecipando o fim do boom. Apesar disso, ela insistiu na manutenção da estratégia de diversificação ainda por alguns anos (ANGLO AMERICAN, 2015a). 0 desempenho do PMR impactou negativamente os resultados econômicos da subsidiária da AA no Brasil (que teve três presidentes em 13 meses) e do grupo como um todo. A redução nos dividendos pagos aos acionistas foi um dos fatores que levou a então CEO do grupo, Cynthia Carroll, a pedir demissão em 2012. Como resposta, o novo CEO, Mark Cutifani, foi escolhido com a expectativa de iniciar a extração de minério em CMD o mais rápido possível (AGOSTINI, 2009; FERREIRA-MARQUES et al., 2012). Na verdade, o início das operações se tornou uma corrida contra o tempo, uma vez que o preço do minério de ferro entrou em seu ciclo descendente, passando de US\$ 151 (2008) para US\$ 96 (2014) (WORLD BANK, 2016). Por fim, o projeto, após atraso de cinco anos, precisou de investimentos adicionais de cerca de US\$ 4 bilhões (AGOSTINI, 2009; ANTONIOLI, 2014).

Em 2015, a AA redefiniu significativamente sua estratégia corporativa, optando por reduzir e concentrar seu portfólio em suas posições de liderança global (diamante, cobre e minérios do grupo platina) (ANGLO AMERICAN, 2016). Nesse processo, anunciou que iria se desfazer de 60\% dos seus ativos e passar de 165 mil para cerca de 50 mil trabalhadores (Anglo American, 2015c). Consequentemente, foi anunciado que a empresa sairia do Brasil; em abril de 2016, a mesma anunciou que venderia seus negócios de nióbio e fosfato para a China Molybdenum (MACDONALD, 2016), e ainda considerou o encerramento de investimentos no PMR, avaliando as possibilidades de sua venda (SHABALALA, 2016).

\section{Estratégias e poder corporativo \\ 4.1. Relações institucionais}

0 exercício de poder corporativo por parte de empresas mineradoras, em geral, é fortemente associado a aspectos econômicos e ideológicos. Previsões habituais de geração de trabalho e renda convertem-se em um léxico persuasivo para agentes estatais, em particular em contextos predominantemente rurais, como no caso de CMD. Em segundo lugar, existe um processo de alinhamento cognitivo entre agentes econômicos e políticos específicos em torno do próprio discurso do crescimento econômico (RIBEIR0, 2008), que legitima a atuação das empresas em grandes projetos e faz convergir prioridades de política pública e a ação de organizações estatais com os interesses corporativos.

Essas características dos projetos minerais comumente fazem com que governos federal, estaduais e locais tomem medidas para favorecer a implementação de grandes projetos extrativistas. Um importante instrumento de facilitação em nível federal diz respeito às isenções fiscais, que reduzem seus custos de instalação e operação. No Brasil, a Lei Complementar 87/1996 isenta os produtos primários e semielaborados destinados à exportação do pagamento do Imposto sobre Operações relativas à Circulação de Mercadorias e sobre Prestações de Serviços (ICMS). Uma segunda forma de 
apoio, em escalas estadual e local, se dá por meio de ações institucionais para facilitar e reduzir os custos associados à desapropriação de áreas necessárias para implementação dos projetos.

No caso específico do PMR, o projeto foi incluído no Regime Especial de Incentivos para o Desenvolvimento da Infraestrutura (REIDI), que diminuiu ainda mais os impostos pagos pela empresa (TOMAZ, 2011). Ainda, o Governo do Estado de Minas Gerais declarou como de utilidade pública as propriedades necessárias para a implantação da cava da mina, usina de beneficiamento e mineroduto, agilizando assim as desapropriações (MINAS GERAIS, 2009).

Essa convergência de interesses tende a ser reforçada pela prática da chamada porta-giratória, comum na América Latina. Esta situação se caracteriza pela mobilidade de profissionais de empresas privadas para cargos públicos, muitas vezes no monitoramento e regulação dos seus setores de origem (cf. ARELLANO-YANGUAS, 2016). No caso brasileiro, tal prática é identificada nas escalas nacional e estadual. Por exemplo, dias após assumir interinamente a Presidência da República, Michel Temer ${ }^{4}$ nomeou um ex-diretor da Vale Fertilizantes para a Secretária de Geologia e Mineração do Ministério de Minas e Energia. Igualmente, o responsável pela Secretaria de Estado de Meio Ambiente e Desenvolvimento Sustentável (SEMAD) de Minas Gerais entre 2015 e 2016 atuou durante anos como consultor ambiental para mineradoras. A AA fez uso da prática, tendo contratado, em 2013, como Gerente de Licenciamento o técnico que, até o ano anterior, era Superintendente de Regularização da SEMAD, e um dos responsáveis pelo processo de licenciamento do PMR (CIMOS, 2013).

Embora questionáveis do ponto de vista ético, tais práticas são consideradas legais no Brasil. Entretanto, elas ainda são reforçadas por práticas ilegais, particularmente pela corrupção de funcionários governamentais. Em Minas Gerais, Adriano Magalhães, secretário estadual de Meio Ambiente entre janeiro de 2011 e abril 2014, foi exonerado de seu cargo por acusação de envolvimento em esquemas de corrupção que beneficiaram o licenciamento ambiental de empresas mineradoras, incluindo a MMX (G1, 2014).

Nesse contexto, os processos de licenciamento tendem a apresentar elementos de parcialidade e favorecimento às empresas. Algumas práticas, como a prerrogativa de classificação de atingidos e não atingidos pelos projetos através de EIAs se encontram institucionalizadas, sendo de difícil reversão. Por outro lado, a aplicação discricionária da legislação, como no caso da fragmentação das etapas do licenciamento, apesar de costumeira, ainda é questionável por representar, de fato, a flexibilização e a retração das exigências ambientais.

De acordo com a legislação ambiental, durante o processo de obtenção da licença prévia, os empreendedores precisam apresentar o EIA. Este estudo, elaborado por empresas de consultoria contratadas pelo empreendimento, deve apresentar não ape-

4. Michel Temer assumiu o cargo após a instauração pelo Senado Federal do processo de impeachment da Presidenta eleita Dilma Rousseff, em 12 de maio de 2016. Contestado por diversos setores da sociedade civil brasileira, desde o inicio o processo vem sendo interpretado como um “golpe parlamentar" (PINHO, 2016). 
nas um diagnóstico da situação corrente, mas também avaliar a relevância dos impactos ambientais e identificar as pessoas atingidas. Sendo a empresa responsável pelo estudo escolhida e remunerada pelo proponente do empreendimento, o processo apresenta explícito conflito de interesses (ZHOURI, 2008).

Em CMD, a definição da população atingida representou ponto importante de conflito. O EIA contratado pela MMX apontava apenas três "núcleos populacionais" dentro da Área de Influência Direta (AID) do projeto: Itapanhoacanga, Córregos e São Sebastião do Bom Sucesso (BRANDT MEIO AMBIENTE, 2007). Esta indicação levou a forte questionamento dos movimentos locais, o que fez com que a concessão da LP fosse condicionada a novos estudos (SISEMA, 2008). Assim, um levantamento elaborado posteriormente identificou um total de 22 comunidades impactadas pelo empreendimento (DIVERSUS AMBIENTE E CULTURA, 2014). Apesar desse avanço, porém, mesmo depois da concessão da LO, seis anos depois, não havia sido elaborada uma lista que contemplasse todos os atingidos (GESTA/UFMG, 2014).

Mesmo com condições favoráveis institucionalizadas, a implantação do PMR foi ainda facilitada por interpretações discricionárias e "flexíveis" da legislação ambiental. Apesar de consistir em um sistema fundamentalmente interligado (mina, mineroduto, porto), a empresa obteve o licenciamento de cada infraestrutura independentemente, bem como cada elemento do sistema foi licenciado por um órgão ambiental distinto. Assim, a mina foi licenciada pelo Governo do Estado de Minas Gerais, o mineroduto pelo Governo Federal e o porto pelo Governo do Estado do Rio de Janeiro. Contraditoriamente, o projeto do mineroduto foi aprovado antes da comprova- ção da viabilidade ambiental da mina e, na verdade, essa aprovação instituiu um "fato consumado", ampliando a pressão política sobre os técnicos que avaliavam os projetos da cava e do porto. Essa estratégia facilitou consideravelmente o licenciamento, uma vez que ocultou os impactos cumulativos e enfraqueceu a articulação dos movimentos sociais, reduzindo a sinergia entre os diferentes movimentos de resistência contra o projeto (BARCELOS, 2013).

Outra tática de fracionamento foi mobilizada em relação às etapas de licenciamento. Em primeiro lugar, a LP foi concedida mediante uma série de condicionantes, fato que representava o perdão por parte do órgão ambiental ao não cumprimento da legislação ambiental (PEREIRA; BECKER; WILDHAGEN, 2013). Por sua vez, como a empresa não se mostrou capaz de cumprir todas as condicionantes definidas na concessão da LP, foi negociada a divisão da LI em duas fases, relativas a etapas distintas da obra - procedimento não previsto pela legislação ambiental brasileira (BARCELOS, 2013). Tal "artimanha” (MELLO; MARTINS; NEFFA, 2015) vem sendo usada de forma crescente na implantação de grandes projetos no Brasil. Por exemplo, "interpretações" com o mesmo grau de flexibilidade foram usadas nos casos das usinas hidrelétricas de Santo Antônio, Jirau e Belo Monte, que obtiveram "Licenças de Instalação Parcial"; nestes casos, apesar de não terem cumprido todas as condicionantes das LPs, as construtoras foram autorizadas a instalar os canteiros de obra dos projetos (FLEURY; ALMEIDA, 2013).

Finalmente, a concessão da LO também apresentou uma série de problemas. Repetindo etapas anteriores, foi concedida independentemente do cumprimento de todas as condicionantes. Além disso, a au- 
diência pública que concedeu a licença foi realizada sob forte coerção das comunidades afetadas, inclusive com a presença da Polícia Militar, que intimidava manifestações contrárias ao licenciamento (GESTA/ UFMG, 2014). 0 uso de força policial como instrumento de intimidação em processos de licenciamento, todavia, não se restringe ao caso do PMR. Por exemplo, em 2014, durante a avalição do projeto do Terminal Portuário de São Luís, no estado do Maranhão, como resposta ao crescente descontentamento das comunidades atingidas, o governo do estado decidiu realizar a audiência pública dentro do Comando Geral da Polícia Militar (SEMA, 2014).

\subsection{Relações territoriais}

Previamente à chegada do PMR, CMD se caracterizava por uma economia baseada em atividades agropecuárias e no pequeno turismo rural, apresentando organizações da sociedade civil pouco afeitas a episódios de contestação social. Não obstante, uma das principais estratégias adotadas pelas empresas mineradoras consistiu na divisão dos grupos que questionavam publicamente o PMR.

Quando a MMX iniciou suas atividades, não havia organizações locais com experiência em conflitos socioambientais. As poucas entidades ambientalistas existentes adotavam um viés preservacionista e com foco em atividades de educação ambiental. Um movimento com caráter de contestação apenas começou a se estruturar com base nos questionamentos dos moradores das áreas rurais; pessoas mais diretamente prejudicadas pela atuação da empresa (Atingido A, entrevista em 25/Jul/2014).

Entretanto, a mobilização foi enfraquecida pela cisão existente entre moradores das áreas urbana e rural. A população que vivia na sede do município via na abertura da mina possibilidades de emprego e de novos negócios, e não sofria tão intensamente os impactos negativos gerados pela atuação da mineradora. Assim, enquanto os moradores das áreas rurais questionavam a implantação e a forma de atuação da empresa, muitos dos moradores da área urbana entendiam como positiva a sua entrada em CMD.

A polarização entre residentes urbanos e rurais foi ampliada, em grande medida, através de uma estratégia territorial focalizada, posta em prática pela AA. Assim, ações de comunicação social foram fundamentais para invisibilizar os impactos gerados nas áreas rurais, tirando proveito da deficiência dos meios de comunicação em CMD e do acesso restrito à informação.

Nesse sentido, a revista Diálogo, publicada bimestralmente pela AA, cumpriu um papel decisivo na conformação da opinião pública em escala local. A revista foi um importante instrumento de apoio à construção da imagem pública da AA. Embora apresentada como "um canal de conversa com os moradores" (PÓS, 2009), seu conteúdo se caracterizava pela seletividade da informação transmitida. Por exemplo, impactos relacionados ao assoreamento, à contaminação hídrica e à restrição do direito humano à água na comunidade da Água Quente, próxima à barragem de rejeitos, foram ignorados. De acordo com o relatório da Diversus Ambiente e Cultura (2011), em Água Quente, os moradores “não estavam utilizando mais a água do córrego em função da intervenção provocada pela mineração em sua cabeceira”. Porém, Tôrres (2014) destaca que, entre os anos 2009 e 2013, todas as menções a esta comunidade na revista foram feitas de maneira positiva; ainda, ações compulsórias de mitigação 
dos impactos, como a instalação das caixas d'água para garantir o suprimento de água, foram representadas como ações voluntárias de responsabilidade social corporativa (RSC) da empresa.

Uma segunda tática de divisão enfocou as ONGs e os movimentos sociais locais, particularmente aqueles que detinham assento na URC Jequitinhonha, responsável pelo licenciamento ambiental do projeto. Por exemplo, ONGs que possuíam convênios, originalmente com a MMX e, posteriormente, com a AA, ocuparam cargos no conselho da URC. Assim, comumente votavam de acordo com os interesses da empresa, em mais uma clara situação de conflito de interesses (Atingido A, entrevista em 10/ Set/2015).

Identificando oportunidades associadas a arranjos informais de propriedade de terra, uma terceira forma de promover a divisão dentro da CMD foi o fomento de conflitos dentro das famílias de produtores rurais. Tradicionalmente, a propriedade e a posse fundiárias em CMD não são transferidas após o falecimento dos proprietários, sendo geridas como "terra de bolo da família”, i.e., em comum acordo, pelos familiares. Esse tipo de arranjo possui elementos de funcionalidade social, uma vez que não é incomum moradores emigrarem temporariamente para centros urbanos; assim como é favorável à manutenção dos descendentes e de suas famílias na propriedade coletiva.

Nesse contexto, as corporações envolvidas na implantação do PMR utilizaram estrategicamente as relações informais de propriedade e posse da terra em CMD e negociaram a "compra" com alguns membros da família, independentemente da concordância de todos os herdeiros ou mesmo da conclusão de inventário, em caso de herança (BARCELOS, 2013). Uma vez 'fechado' o negócio, proibia-se a entrada dos moradores e herdeiros nos terrenos (Atingido B, entrevista em 10/set/2015). Muitas pessoas, assim, perderam acesso às terras sem receber qualquer indenização. Como muitos dos moradores das áreas rurais possuíam baixa escolaridade, além de dificuldade de acesso à informação e a serviços públicos (como cartórios e defensoria), não conseguiram reverter tal situação por meio da justiça.

$\mathrm{Na}$ verdade, em muitos casos, instrumentos jurídicos foram amplamente utilizados pela AA na resolução de conflitos fundiários. Um levantamento feito entre setembro de 2015 e abril de 2016 no Tribunal de Justiça do Estado de Minas Gerais identificou a AA como autora de 94 ações judiciais. Desse total, 64 eram ações de efetivação e garantia das servidões administrativas ou decorrentes de direito real, associadas à lavra ou à construção do mineroduto (PAIVA; ÁVILA, 2016).

Ainda, o exercício do poder corporativo da AA em CMD incorporou práticas de violência física e simbólica. A violência no campo é um elemento presente de forma quase estrutural na sociedade brasileira. A Comissão Pastoral da Terra (CPT) sistematiza e analisa os conflitos no campo desde 1985. Em 2015, foram identificados 998 conflitos de terra envolvendo mais de 600 mil pessoas e resultando em 47 assassinatos (CANUTO; LUZ; ANDRADE, 2016).

No caso de CMD, a violência apresentou diferentes formas. Santos (2014) identificou um processo de "encurralamento" dos residentes rurais resistentes aos acordos de aquisição de terras. A aquisição de propriedades extensas e com localização estratégica representou uma de suas expressões diretas. A AA teria fechado acessos tradicionais que atravessavam as terras adquiridas, assim como teria destruído benfeitorias existentes e aban- 
donado seu entulho, explicitando uma tática de “terra arrasada". A redução da mobilidade e a desocupação do entorno gerariam nos moradores "um sentimento de solidão devido ao esvaziamento do espaço social” (SANTOS, 2014), reduzindo sua capacidade de resistência e facilitando as negociações.

Ameaças e uso direto da violência contra opositores do PMR também foram verificadas. Como exemplo, em uma atividade de campo realizada em maio de 2013 por um grupo de pesquisadores (dentre os quais, um dos autores deste artigo), a tentativa de visitar a propriedade de uma moradora de CMD foi frustrada em razão do fechamento da estrada por cancela e caminhonete de equipe de segurança privada da AA. Posteriormente, seguranças da empresa passaram a seguir ostensivamente e a filmar tanto os pesquisadores quanto as pessoas com quem conversavam ao longo do dia. De forma semelhante, há relatos de seguranças da empresa que queimaram acampamentos de moradores que se recusavam a sair de suas terras (Atingido B, entrevista em 10/set/2015).

Formas adicionais de intimidação de moradores em favor da corporação e realizadas por parte de indivíduos não diretamente vinculados a ela foram igualmente registradas. Por exemplo, o advogado Élcio Pacheco, representante de diferentes famílias impactadas pelo projeto, denunciou a atuação de um sargento reformado da Polícia Militar que vinha intimidando moradores, inclusive na frente de outros policiais, à Comissão de Direitos Humanos da Assembleia Legislativa de Minas Gerais (ALMG, 2013). Ainda, há relatos de informantes das empresas; pessoas da comunidade ou de fora, que observam e delatam o comportamento e as ações dos atingidos, o que cria insegurança e desconfiança entre os moradores (Atingido B, entrevista em 10/ set/2015).

Assim, as táticas de divisão contribuíram para reduzir a resistência e a contestação ao projeto. Mesmo entre os movimentos sociais, militantes e atingidos foram reduzindo suas atividades. Pereira; Becker e Wildhagen (2013) relatam que nas reuniões realizadas junto ao Ministério Público foram identificadas situações de incerteza, insegurança e cansaço emocional.

\section{Considerações finais}

Ao longo do artigo, utilizamos o PMR para ilustrar diferentes aspectos associados à expansão de grandes projetos extrativos no Brasil ao longo da primeira década dos anos 2000. 0 caso mostra diferentes aspectos estruturais relacionados às instituições e à sociedade no Brasil, que ajudam a entender o processo que ampliou a participação das atividades extrativas no país, assim como os respectivos conflitos socioambientais.

Para tanto, primeiramente contextualizamos os períodos do boom das commodities e de seu encerramento, associando o (in)fluxo e a velocidade de implantação de novos projetos extrativos ao ciclo dos preços das commodities minerais no mercado internacional. Em seguida, descrevemos aspectos gerais da rede de produção mineral brasileira, o contexto institucional de controle ambiental, bem como aspectos gerais da AA e do PMR. A partir de então, descrevemos duas dimensões específicas de atuação das empresas extrativas - institucional e territorial - identificando aspectos gerais e analisando como a AA buscou se beneficiar de tal contexto.

Por um lado, o estudo reforçou aspectos já identificados na literatura sobre ex- 
trativismo, como o alinhamento cognitivo entre empresa e agentes públicos em torno do crescimento econômico (RIBEIR0, 2008) e o uso de diferentes formas de violência e de violação de direitos humanos (SAUNDERS, 2014). Por outro lado, o caso apresenta novos elementos a serem considerados, particularmente (1) a fragmentação dos processos de licenciamento, indicando um processo de flexibilização "de fato" na regulação ambiental em grandes projetos no Brasil e; (2) a crescente mobilidade territorial das empresas extrativas, em um contexto de elevada financeirização de seu controle.

No campo do licenciamento ambiental, muitas das "artimanhas" identificadas no caso do PMR se deram de forma discricionária e pontual, entre elas, a definição das comunidades afetadas e a fragmentação do projeto. Porém a partir de tais "experiências” pode ser inferido um novo ciclo de institucionalização da flexibilização e da redução do rigor na avaliação de grandes projetos. Assim, em dezembro de 2015, foi levado ao plenário da Assembleia Legislativa de Minas Gerais o projeto de lei 2.946/2015, aprovado no ano seguinte na forma da Lei 2.1972/2016. A nova legislação não apenas restringia o tempo de avaliação dos Estudos de Impacto Ambiental pelos órgãos ambientais, como ainda permitia que os licenciamentos de projetos fossem debatidos pelo COPAM ou URCs sem a devida análise pelos órgãos competentes.

Propostas semelhantes também começaram a ser apresentadas ao Poder Legislativo em nível federal. Em abril de 2016, foi aprovada na Comissão de Constituição, Justiça e Cidadania do Senado Federal a Proposta de Emenda à Constituição n ${ }^{\circ}$ 65/2012. Se aprovada, ela definirá que a apresentação do estudo prévio de impacto ambiental constitui autorização para a execução de obras, além de impedir a sua suspensão ou cancelamento. Assim, essa proposta definirá que a simples apresentação de um estudo prévio garantiria a autorização para o início dos empreendimentos.

Outro elemento importante identificado no texto diz respeito à crescente mobilidade das empresas extrativistas. Investimentos minerais são normalmente caracterizados por serem intensivos em capital, com elevados custos irrecuperáveis (sunk costs) e longos períodos de retorno. Por essas características, grandes empresas mineradoras eram vistas como investimentos sólidos, com baixa mobilidade e fortes vínculos territoriais. 0 exemplo do PMR, entretanto, sugere uma alteração nesse sentido. Por cerca de oito anos, a AA lutou agressivamente pela implantação do PMR, conseguindo as licenças necessárias e iniciando sua operação. Mudanças no cenário internacional, porém, levaram a retornos abaixo daqueles esperados pelos acionistas. Em resposta, a empresa sinalizou rapidamente a transferência do empreendimento. Esse comportamento sugere, portanto, que as empresas mineradoras, em um contexto de elevada financeirização, podem passar a adotar decisões mais voláteis e instáveis, o que irá mudar significativamente a forma como se relacionam com Estado e com comunidades em seu entorno.

Em síntese, o artigo presta uma contribuição à literatura sobre extrativismo ao realizar uma análise integrada dos condicionamentos estruturais dos cenários de boom das commodities e de seu encerramento sobre as formas de regulação institucional - em especial, ambiental - da indústria extrativa mineral e estratégias corporativas de mineradoras major no Brasil, ten- 
do como caso exemplar a implantação e o potencial de investimento da AA no PMR. Dessa forma, sublinha-se a necessidade de estudos de caso similares, investigando a conformação de estratégias corporativas no setor em segmentos de mercado e localidades diversas, com vistas ao aprofundamento da compreensão dos efeitos territoriais das atividades extrativas minerais no Brasil e na América Latina, em particular no que se refere ao período do pós-boom, que se iniciou em 2012.

\section{Referências}

AGB. Relatório dos impactos socioambientais do complexo industrial-portuário do Açu. Rio de Janeiro: Associação dos Geógrafos Brasileiros, 2011.

AGOSTINI, R. No papel parecia fácil. Revista Exame, 29 jul. 2016. Disponivel em: http:// exame.abril.com.br/revista-exame/edicoes/956/ noticias/papel-parecia-facil-511296. Acesso em: 12 nov. 2017.

ALMG. Transcrição da 17a Reunião Extraordinária da Comissão de Direitos Humanos. Belo Horizonte: 2013.

ANGLO AMERICAN. Annual Report 2012. London: Anglo American plc, 2013.

Annual Report 2014. London: Anglo American plc., 2015a.

History. Disponível em: http://www. angloamerican.com/about-us/history. Acesso em: 24 sep. 2015.

Investor day 2015: driving change, defining our future. Disponivel em: http://www. angloamerican.com/ /media/Files/A/Anglo-American-PLC-V2/presentations/2015pres/investor-day2015-presentation.pdf. Acesso em: 22 jul. 2016.

Annual Report 2015. London: Anglo

American plc., 2016.
ANTONIOLI, S. Anglo American embarca $1^{\circ}$ carregamento de minério de ferro do projeto Minas-Rio. Reuters, 29 jul. 2016. Disponível em: http:// br.reuters.com/article/businessNews/idBRKBNOIG0ZS20141027. Acesso em: 27 out. 2017.

ANTT. Relatório Anual 2011. Brasília: Agência Nacional de Transportes Terrestres, 2012.

ARELLANO-YANGUAS, J. Mining policies in Humala's Peru. In: HASLAM, P. A.; HEIDRICH, P. (Eds.). The political economy of natural resources and development: from neoliberalism to resource nationalism. New York: Routledge, 2016, p. 173-190.

BARCELOS, E. 0 projeto Minas Rio e seus impactos socioambientais: olhares desde a perspectiva dos atingidos. Rio de Janeiro: Instituto Brasileiro de Pesquisa Socio Econômica, 2013.

BRANDT MEIO AMBIENTE. Estudo de impacto ambiental: lavra a céu aberto para produção de 56 milhões de toneladas por ano, tratamento de minério de ferro e infra-estrutura de produção. Nova Lima: Brandt Meio Ambiente Ltda, 2007.

BRIDGE, G. Global production networks and the extractive sector: governing resource-based development. Journal of Economic Geography, vol. 8, n. 3, p. 389-419, 2008.

CANUTO, A.; LUZ, C. R. D. S.; ANDRADE, T. V.

P. Conflitos no campo no Brasil 2015. Goiânia: Comissão Pastoral da Terra, 2016.

CARNEIRO, E. J. A oligarquização da política ambiental mineira In: ZHOURI, A.;LASCHEFSKI, K.; PEREIRA, D. B. (Orgs.). A insustentável leveza da política ambiental: desenvolvimento e conflitos ambientais. Belo Horizonte: Autêntica, 2005, p. 65-88.

CETEM. Exploração de minério de ferro em Conceição do Mato Dentro (MG) afeta meio social e ambiente. In: CETEM (Org.). Banco de dados de recursos minerais e territórios: impactos humanos, socioambientais e econômicos. Rio de Janeiro: CETEM, 2012.

CIMOS. Ata da 8a. Reunião Pública da Reasa, 18 
de fevereiro de 2013. Belo Horizonte: Coordenadoria de Inclusão e Mobilização Sociais, Ministério Público de Minas Gerais, 2013.

COELHO, T. P. Noventa por Cento de Ferro nas Calçadas: mineração e (sub)desenvolvimento em municípios minerados pela Vale S.A. 2016. 300 p. (Doutorado). Programa de Pós-graduação em Ciências Sociais, Universidade do Estado do Rio de Janeiro, Rio de Janeiro.

COHEN, T. Anglo American: requiem for an icon. Financial Mail, 3 mar. 2016. Disponivel em: http://www.financialmail.co.za/coverstory/2016/03/03/anglo-american-requiem-for-an-icon. Acesso em: 25 jul. 2016.

COMMODITIES NOW. Mining Exploration Trends. Commodities Now: LME Week Supplement, n. 4, 2015.

CONCEIÇÃO, P.; MARONE, H. Characterizing the 21st Century First Commodity Boom: drivers and impact. UNDP/ODS Working Paper, vol. 102, 58 p., 2008.

COPAM. Deliberação COPAM n 476 , de 24 de maio de 2013. Belo Horizonte: Conselho Estadual de Política Ambiental de Minas Gerais, 2013a.

Deliberação COPAM nº 484 de maio de 2013. Belo Horizonte: Conselho Estadual de Política Ambiental de Minas Gerais, 2013b.

DIVERSUS AMBIENTE E CULTURA. Diagnóstico socioeconômico da área diretamente afetada e da área de influência direta do empreendimento Anglo Ferrous Minas-Rio Mineração S.A. Belo Horizonte: Diversos Consultores Associados Ltda, 2011.

. Estudo de definição sobre comunidades/ famílias a serem reassentadas. Belo Horizonte: Mimeo, 2014.

DNPM. Sumário Mineral. Brasília: Departamento Nacional de Produção Mineral, 2012.

Maiores Arrecadadores CFEM. Disponí-

vel em: https://sistemas.dnpm.gov.br/arrecadacao/ extra/Relatorios/cfem/maiores_arrecadadores. aspx. Acesso em: 12 abr. 2016.
ELLA. Mining in Latin America: attracting quantity and quality in FDI. 2012.

EUCLYDES, A. C. P. Proteção da natureza e produção da natureza: política, ideologias e diversidade na criação de unidades de conservação na periferia sul da metrópole belo-horizontina. 2012. (M.Sc.). Programa de Pós-graduação em Geografia, Universidade Federal de Minas Gerais, Belo Horizonte.

FELLOWS, M. How Does The Mining Sector Cycle Play Out? Insights for Industry Suppliers. SNL Metals \&t Mining, 2015.

FERREIRA-MARQUES, C. et al. Pressionada, CEO da Anglo American Cynthia Carrol pede demissão. Reuters, 29 jul. 2016. Disponivel em: http://br.reuters.com/article/topNews/idBRSPE89P04620121026?pageNumber=2\&tvirtualBrandChannel=0\&tsp=true. Acesso em: 26 out. 2016.

FLEURY, L. C.; ALMEIDA, J. P. A construção da usina hidrelétrica de Belo Monte : conflito ambiental e o dilema do desenvolvimento. Ambiente \&t Sociedade, vol. 16, n. 4, p. 141-158, 2013.

G1. MP denuncia secretário estadual de Meio Ambiente da gestão Anastasia. G1 Minas Gerais, 02 ago. 2016. Disponível em: http://g1.globo. com/minas-gerais/noticia/2014/06/mp-denunciasecretario-estadual-de-meio-ambiente-da-gestao-anastasia.html. Acesso em: 05 jun. 2017.

GESTA/UFMG. GESTA/UFMG. A uma semana das eleições, Anglo manda e governo de Minas obedece. Disponivel em: http://conflitosambientaismg.lcc.ufmg.br/noticias/a-uma-semana-das-eleicoes-anglo-manda-e-governo-de-minas-obedece/. Acesso em: 28 Jan 2015.

GÓES, F.; ROSAS, R. Vale vende mina de carvão na Austrália por valor simbólico. Valor Econômico, 30 jul. 2015. Disponível em: http://www.valor. com.br/empresas/4157052/vale-vende-mina-decarvao-na-australia-por-valor-simbolico. Acesso em: 9 set. 2015 .

HOYLE, R. Titãs do minério de ferro tiram pequenos concorrentes do mercado. The Wall Street Journal, 15 ago. 2015. Disponivel em: http://br. 
wsj.com/articles/SB1280734911633086384330 4581124783354874852?tesla=y. Acesso em: 23 jul. 2016.

IBGE. Contas regionais do Brasil 2010-2013. Rio de Janeiro: Instituto Brasileiro de Geografia e Estatística, 2015.

Cidades@.Disponível em: www.cidades. ibge.gov.br. Acesso em: 02 Jul 2016.

IBRAM. Informações e análises da economia mineral brasileira. Brasília: Instituto Brasileiro de Mineração, 2012.

Informações sobre a economia mineral brasileira 2015. Brasília: Instituto Brasileiro de Mineração, 2015.

IISI. Steel Statistical Yearbook 2003. Brussels: International Iron and Steel Institute,, 2014.

LEIJH, V. P. J. The attractiveness of juniors in the mining industry. 2013. 134 p. (MA). Erasmus University Rotterdam

LOPES, F.; ROSTÁS, R. CMOC, da China, adquire ativos da Anglo American. Valor Econômico, 29 abr. 2016. Disponivel em: http://www.valor.com. br/agro/4543185/cmoc-da-china-adquire-ativosda-anglo-american. Acesso em: 30 mai. 2016.

MACDONALD, A. Anglo American to sell Brazilian niobium and phosphates businesses to China Molybdenum. The Wall Street Journal, 22 jul. 2016. Disponivel em: http://www.wsj.com/ articles/anglo-american-to-sell-brazilian-niobium-and-phosphates-businesses-to-china-molybdenum-1461824607. Acesso em: 28 abr. 2017.

MATTERA, P. Anglo American's track record: rhetoric or reality. Nunamta Aulukestai; Renewable Resources Coalition, 2008.

MELLO, D. S.; MARTINS, M. B.; NEFFA, E. Vaudeville ambiental: um estudo sobre estratégias e táticas em licenciamento de empreendimentos, o caso do Campo de Dunas do Peró, Cabo Frio - RJ. Niterói: Programa de Pós-graduação em Sociologia e Direito, Universidade Federal Fluminense, 2015.
MILANEZ, B.; SANTOS, R. S. P. Topsy-turvy neodevelopmentalism: an analysis of the current Brazilian model of development. Revista de Estudios Sociales, vol. 53, p. 12-28, 2015.

MINAS GERAIS. Decreto $n^{\circ}$ 42.595, de 23 de maio de 2002. Belo Horizonte: 2002.

Decreto de 13 de julho de 2009. Belo Horizonte: 2009. Decreto $\mathrm{n}^{\circ} 46.501$, de 5 de maio de 2014 Belo Horizonte: 2014.

NIEPONICE, G. et al. Value Creation in Mining 2015: beyond basic productivity. 2015.

PAIVA, L. M.; ÁVILA, N. S. M. C. Relatório sobre os dados processuais referentes à Anglo American e sociedades empresárias conexas extraídos do Tribunal de Justiça do Estado de Minas Gerais (TJMG). Juiz de Fora: Faculdade de Direito, Universidade Federal de Juiz de Fora, 2016.

PATTERSON, S.; MACDONALD, A. Anglo American Just Scratching Surface in Effort to Slim Down. Wall Street Journal, 26 jul. 2016. Disponível em: http://www.wsj.com/articles/anglo-american-just-scratching-surface-in-effort-to-slim-down-1469534427. Acesso em: 28 jul. 2016.

PEREIRA, D. C.; BECKER, L. C.; WILDHAGEN, R. O. Comunidades atingidas por mineração e violação dos direitos humanos: cenários em Conceição do Mato Dentro. Revista Ética e Filosofia Política, vol. 16, n. 1, p. 124-150, 2013.

PINHO, C. E. S. Emergência e Declínio do Governo Dilma Rousseff à Luz das Capacidades do Estado Brasileiro (2011-2016). Revista Brasileira de Planejamento e Orçamento, vol. 6, n. 1, p. 94-121, 2016.

PÓS, W. Editorial: boas vindas. Belo Horizonte: Anglo American, 2009.

PUK0, T. Gigantes da mineração são forçadas a se diversificar para resistir à crise. The Wall Street Journal, 15 ago. 2015. Disponivel em: http://br. wsj.com/articles/SB125593014591752341923045 81183192537566426. Acesso em: 23 jul. 2016. 
RAJAK, D. In good company. An anatomy of Corporate Social Responsibility. Stanford, CA: Stanford University Press, 2011.

RIBEIR0, G. L. Poder, redes e ideologia no campo do desenvolvimento. Novos Estudos-CEBRAP, $\mathrm{n}$. 80, p. 109-125, 2008.

ROBERTS, I. et al. China's Evolving Demand for Commodities. In: DAY, I.; SIMON, J. Structural Change in China: Implications for Australia and the World, 2016, Reserve Bank of Australia, 17-18 March 2016. p.46.

SANTOS, A. F. M. Não se pode proibir comprar e vender terra: terras de ocupação tradicional em contexto de grandes empreendimentos. In: ZHOURI, A.; VALENCIO, N. (Orgs.). Formas de matar, de morrer e de resistir: limites da resolução negociada de conflitos ambientais. Belo Horizonte: Editora UFMG, 2014, p. 143-165.

SANTOS, R. S. P. D.; MILANEZ, B. Historical Data. 2016.

SAUNDERS, R. Geologies of power: blood diamonds, security politics and Zimbabwe's troubled transition. Journal of Contemporary African Studies, vol. 32, n. 3, p. 378 - 394, 2014.

SEMA. Edital de covocação de audiência pública. Sçao Luís: Secretaria de Estado do Meio Ambiente e Recursos Naturais, 2014.

SHABALALA, Z. Anglo American planeja vender ativos de minério; analisará opções para Minas-Rio. Reuters, 07 ago. 2016. Disponível em: http://br.reuters.com/article/topNews/idBRKCNOVP1QU. Acesso em: 16 fev. 2017.

SISEMA. Anglo Ferrous Minas-Rio Mineração S.A - Parecer único SISEMA no. 001/2008. Diamantina: Sistema Estadual de Meio Ambiente de Minas Gerais, 2008.

THE TELEGRAPH. Australia's mining boom is over, says resources minister Martin Ferguson. The Telegraph, 23 ago. 2012. Disponivel em: http://www.telegraph.co.uk/finance/newsbysector/industry/mining/9493824/Australias-mining-boom-is-over-says-resources-minister-Martin-
Ferguson.html. Acesso em: 30 set. 2015.

TOMAZ, R. Projeto Minas-Rio foi incluído no programa REIDI. Diário do Comércio, 2 ago. 2016. Disponivel em: http://www.diariodocomercio.com.br/noticia.php?id=48024. Acesso em: 8 jan. 2017.

TÔRRES, M. A. Histórias de água e minério: os efeitos do Projeto Minas-Rio em Água Quente, Conceição do Mato Dentro. 2014. p. (B.Sc.). Faculdade de Filosofia e Ciências Humanas, Universidade Federal de Minas Gerais, Belo Horizonte.

UNTD. World Investment Report 2016. UNTD, 2016.

VIANA, M. B.; BURSZTYN, M. A. A. Regularização ambiental de minerações em Minas Gerais. REM: Revista Escola de Minas, vol. 63, n. 2, p. 363-369, 2010.

VILAÇA, R. Transporte ferroviário de cargas no Brasil. $8^{\circ}$ Encontro de Logística e Transportes, 2013, São Paulo. Federação das Indústrias do Estado de São Paulo, 06 Mai.

WANDERLEY, L. J. D. M. Geografia da Mineração de Ouro no Mundo da Globalização Financeira. Revista Tamoios, vol. 11, n. 2, p. 22-49, 2015.

WILSON, J. D. Governing global production resource networks in the Asia-Pacific steel industry. Hampshire: Palgrave Macmillan, 2013.

WORLD BANK. World Bank Commodity Price Data (The Pink Sheet). 2016.

WSA. World Steel in Figures 2014. Brussels: World Steel Association,, 2014.

ZHOURI, A. Justiça ambiental, diversidade cultural e accountability: desafios para a governança ambiental. Revista Brasileira de Ciências Sociais, vol. 23, n. 68, p. 97-107, 2008.

. Mapeando desigualdades ambientais: mineração e desregulação ambiental. In: ZHOURI, A.; VALENCIO, N. (Orgs.). Formas de matar, de morrer e de resistir: limites da resolução negociada de conflitos ambientais. Belo Horizonte: Editora UFMG, 2014, p. 111-141. 


\section{RESUMO}

0 artigo discute as transformações nos mercados de commodities ao longo das duas últimas décadas, as estratégias corporativas de adaptação a tais mudanças e seus rebatimentos institucionais. 0 estudo avalia a implantação e a expansão do Projeto Minas-Rio, da Anglo American, em Conceição do Mato Dentro (MG). A pesquisa é baseada em análise documental, observação participante e entrevistas semiestruturadas, e foca em táticas corporativas voltadas para influência e controle das instituições e movimentos de contestação, tais como cooptação, controle da informação, judicialização e intimidação. 0 caso é interpretado como prenúncio da institucionalização da flexibilização do licenciamento ambiental em Minas Gerais. A análise sugere como a financeirização vem determinando crescente desterritorialização de empresas extrativas.

\section{PALAVRAS-CHAVE}

Mineração. Conflitos ambientais. Poder corporativo. Vulnerabilidade institucional. Licenciamento ambiental.

\section{ABSTRACT}

In the text, we discuss the transformations in commodity markets over the last two decades, the adaptive corporate strategies related to those changes, and their institutional outcomes. The study assesses the implementation and expansion of the Anglo American's Minas-Rio Project in Conceição do Mato Dentro (MG). The research is based on document analysis, participant observation and semi-structured interviews and focuses on corporate tactics aimed at influencing and controlling state organizations and social movements such as co-optation, information control, prosecution and intimidation. We interpret the case as foreshadowing the institutionalization of relaxation procedures towards environmental licensing in Minas Gerais. The analysis suggests how financialization has been driving the increasing deterritorialization of extractive corporations.

\section{KEYWORDS}

Mining. Environmental conflicts. Corporate power. Institutional vulnerability. Environmental licensing.

Recebido em: 13/04/2018

Aprovado em: 06/05/2019 